\title{
Pengaruh Latihan Penguatan Dengan Elastic Band Dalam Meningkatkan Kemampuan Pasien Osteoarthritis Knee Di Rumah Sakit Condong Catur Sleman
}

\author{
W Wahyuni ${ }^{1}$, Ricky Fauzi Zakaria ${ }^{2}$ \\ ${ }^{1}$ Program Studi Fisioterapi, Fakultas Ilm Kesehatan, Universitas Muhammadiyah Surakarta \\ Jl. A. Yani Tromol Pos I Pabelan Kartasura Telp. (0271) 717417 Fax. (0271) 715448 \\ Surakarta 57162 \\ ${ }^{2}$ Rumah Sakit Condong Catur, Sleman \\ Email: ${ }^{1}$ wahyuni@ums.ac.id \\ 2 ricky.fzak@gmail.com
}

Tanggal Submisi: 8 Januari 2021; Tanggal Penerimaan: 21 Juni 2021

\begin{abstract}
ABSTRAK
Latar Belakang: Latar Belakang: Osteoartritis merupakan penyakit degeneratif yang disebabkan oleh kerusakan tulang rawan sendi. Gejala utama osteoartritis adalah gangguan nyeri dan pergerakan yang dapat mempengaruhi gangguan fungsional. Prevalensi osteoartritis lutut di Indonesia cukup tinggi yaitu mencapai $15,5 \%$ pada pria dan $12,7 \%$ pada wanita. Diperkirakan 1 hingga 2 juta lansia di Indonesia menderita cacat akibat osteoartritis. Pengobatan osteoartritis ditujukan untuk mengurangi nyeri, meningkatkan kemampuan fungsional, dan mencegah deformitas. Latihan penguatan elastic band merupakan latihan yang dapat digunakan untuk mengurangi nyeri, meningkatkan kekuatan otot dan kemampuan fungsional.

Tujuan: Penelitian ini bertujuan untuk mengetahui pengaruh latihan penguatan elastic band dalam meningkatkan kemampuan fungsional osteoartritis lutut.

Metode: Metode yang digunakan dalam penelitian ini adalah eksperimen semu dengan desain control group pre and post-test. Jumlah responden penelitian ini adalah 20 responden yang terdiagnosis osteoartritis lutut di RSUD Condong Catur Sleman. Responden dibagi secara acak menjadi dua kelompok yaitu kelompok perlakuan yang mendapat perlakuan senam penguatan elastic band dan kelompok kontrol yang mendapat perlakuan standar yang diberikan di rumah sakit. Pengobatan diberikan dua kali seminggu selama empat minggu. Pengukuran kemampuan fungsional dilakukan dengan menggunakan skor WOMAC.

Hasil: Terjadi penurunan tingkat nyeri pada kelompok perlakuan, sedangkan pada kelompok kontrol tingkat nyeri masih sama dengan sebelumnya. Pada kemampuan fungsional terjadi peningkatan pada kelompok perlakuan. Uji statistik menunjukkan bahwa terdapat pengaruh antara kelompok perlakuan dan kelompok kontrol.

Kesimpulan: Latihan penguatan elastic band efektif meningkatkan kemampuan fungsional pada osteoartritis lutut di RSUD Condong Catur Sleman.

Kata kunci: latihan penguatan elastic band, kemampuan fungsional, osteoartritis lutut
\end{abstract}

\section{ABSTRACT}

Background: Osteoarthritis is a degenerative disease caused by joint cartilage damage. The main symptoms of osteoarthritis are pain and movement disorders that can affect the functional disorders. The prevalence of knee osteoarthritis in Indonesia is quite high, reaching $15.5 \%$ in men and $12.7 \%$ in 
women. It is estimated that 1 to 2 million older people in Indonesia suffer from disabilities due to osteoarthritis. Osteoarthritis treatment is intended to reduce pain, improve functional ability, and prevent deformity. Elastic band strengthening exercises are exercises that can be used to reduce pain, increase muscle strength and functional ability.

Objective: This study aims at determining the effect of elastic band strengthening exercises in improving knee osteoarthritis functional capabilities.

Method: The method used in this study was quasi-experimental with pre and post-test control group design. The number of respondents of this study was 20 respondents diagnosed with knee osteoarthritis in Condong Catur Hoselastic bandl Sleman. Respondents were randomly divided into two groups, namely the treatment group that received elastic band strengthening exercise treatment and the control group that received standard treatment given at the hoselastic bandl. The treatment was given twice a week for four weeks. Measurement of functional ability was done using WOMAC score.

Results: There was a decrease in pain level in the treatment group, while in the control group, the pain level was still the same as before. In the functional ability, there was an increase in the treatment group. The statistical test showed that there was an influence between the treatment group and the control group.

Conclusion: Elastic band strengthening exercises effectively improved functional capabilities in knee osteoarthritis in Condong Catur Hoselastic bandl Sleman.

Keywords: elastic band strengthening exercises, functional capabilities, knee osteoarthritis

\section{LATAR BELAKANG}

Osteoartritis adalah suatu kondisi di mana tulang rawan sendi mengalami kerusakan yang ditandai dengan adanya perubahan pada kapsul sendi. Osteoartritis biasanya menyerang sendi yang menahan beban, seperti pinggul, lutut, tulang belakang, tetapi juga dapat memengaruhi bahu, sendi jari, dan pergelangan kaki. (Carlos, 2013).

Jumlah penderita osteoartritis di seluruh dunia sekitar 151 juta orang dan sekitar 24 juta di Asia Tenggara. Prevalensi osteoartritis juga terus meningkat secara dramatis seiring bertambahnya usia pasien. Berdasarkan temuan radiologi, ditemukan sekitar $70 \%$ pasien berusia di atas 65 tahun menderita osteoartritis. Keadaan ini menunjukkan bahwa usia, jenis kelamin, dan obesitas berhubungan dengan osteoartritis lutut (Suhendriyo, 2014).

Osteoartritis lutut dapat terjadi karena berbagai faktor, baik faktor primer maupun sekunder. Faktor utama tidak diketahui. Jenis osteoartritis lutut ditemukan pada usia paruh baya, sedangkan faktor sekunder dapat disebabkan oleh sinovial (Rasjad, 2009). Peningkatan jumlah usia lanjut dan usia harapan hidup akan berdampak besar pada kesehatan masyarakat, terutama dengan adanya perubahan yang dialami lansia pada berbagai sistem tubuh (Wirahardja dan Satya, 2014). Menurut Setiati (2013), penuaan merupakan penurunan fungsi fisiologis dan kognitif secara progresif dan terdapat peningkatan kerentanan pada usia lanjut. Laju dan dampak proses penuaan berbeda untuk setiap individu 
dan dipengaruhi oleh faktor genetik dan lingkungan.

Secara umum gejala penuaan dimulai sejak usia 45 tahun dan timbul permasalahan pada usia sekitar 60 tahun. Gambaran penurunan fungsi tubuh lansia terkait kekuatan / energi menurun $88 \%$, fungsi penglihatan menurun $72 \%$, kelenturan tubuh menurun $64 \%$, daya ingat menurun $61 \%$, pendengaran menurun $67 \%$ dan fungsi seksual menurun 86\% (Umur, 2010). Pada lansia banyak terjadi kasus degeneratif, salah satunya adalah nyeri muskuloskeletal. Penurunan sistem muskuloskeletal dapat mempengaruhi dan mengganggu mobilitas fisik. Salah satu kelainan muskuloskeletal yang sering terjadi pada lansia adalah osteoartritis.

Osteoartritis (selanjutnya disebut OA) di lutut menyebabkan lebih banyak kecacatan daripada sendi lainnya. Keluhan utama osteoartritis lutut terbatas pada gerakan dan aktivitas fungsional (Age, 2010). Keluhan lain dari OA lutut, seperti nyeri, kaku, otot lemas, dan kesejajaran abnormal. Nyeri terjadi karena beberapa faktor. Lama nyeri akan mengakibatkan kelemahan otot dan ketidakstabilan sendi lutut. Kasus osteoartritis lutut yang parah akan berdampak pada aktivitas fungsional yang dapat mengganggu aktivitas sehari-hari, seperti berdoa, buang air kecil, dan buang air besar (toileting), berpakaian, mengurus rumah tangga, dan aktivitas kerja (Susilawati et al., 2015).

Salah satu perawatan yang dapat dilakukan untuk OA lutut adalah latihan penguatan. Latihan penguatan adalah latihan aktif yang dilakukan oleh masyarakat sendiri. Latihan penguatan ada dua macam, yaitu latihan dinamis dan latihan statis, dengan tahanan luar. Gerakan aktif dilakukan dengan kontraksi otot-otot yang akan mengaktifkan kontrol motorik dan otot. Mekanisme latihan penguatan selama ini akan menyebabkan peningkatan vasodilatasi dan metabolisme pembuluh darah yang akan mengurangi nyeri dan menghindari kejang otot. Selanjutnya kontraksi otot akan merangsang jaringan kontraktil untuk menghasilkan ketegangan pada otot untuk menghasilkan kekuatan (Kisner \& Colby, 2018). Salah satu alat bantu latihan penguatan adalah elastic band. Elastic band adalah alat sederhana yang digunakan untuk berbagai macam latihan fisik. Menurut Riberio dkk. (2009), latihan beban dengan menggunakan elastic band memiliki keunggulan seperti elastic band paha depan dan karung pasir. Kurva deformasi elastic band dikaitkan dengan peningkatan kekuatan dan nilai tegangan. Semakin besar elastic band yang diregangkan, semakin kuat tahanannya terhadap kekuatan otot. Menggunakan elastic band adalah cara mudah untuk meningkatkan intensitas latihan sekaligus menghindari risiko kelebihan beban. Alat ini digunakan karena elastisitas dan kemampuannya untuk kembali ke ukuran aslinya. (Uchida, 2016). Berdasarkan latar belakang di atas maka peneliti tertarik untuk mengelola aktivitas fisioterapi fungsional pada pasien osteoartritis lutut. Untuk itulah maka peneliti melakukan penelitian yang berjudul Pengaruh Latihan Penguatan Elastic band Dalam Meningkatkan Kemampuan Fungsional Penderita Osteoartritis Lutut Di RSUD Condong Catur Sleman.

\section{TUJUAN}


Penelitian ini bertujuan untuk mengetahui pengaruh latihan penguatan elastic band dalam meningkatkan kemampuan fungsional osteoartritis lutut.

\section{METODE}

Penelitian ini merupakan penelitian eksperimen semu, dengan desain control group pre and post test. Penelitian dilakukan pada bulan Januari-Februari 2020. Penelitian dilakukan di Rumah Sakit Condong Catur Sleman Yogyakarta. Populasi dalam penelitian ini adalah semua pasien dengan kriteria inklusi yaitu terdiagnosis osteoartritis derajat 1 dan 2 menurut Kellgren dan Lawrence usia 50-65 tahun, tidak menggunakan alat bantu dan tidak mengalami gangguan neurologis. Kriteria eksklusi dalam penelitian ini adalah pasien post total knee replacement (TKR). Teknik pengambilan sampel yang digunakan dalam penelitian ini adalah teknik total sampling.

Variabel terikat dalam penelitian ini adalah kemampuan fungsional pasien osteoartritis lutut. Kemampuan fungsional diartikan sebagai kemampuan seseorang dalam melakukan aktivitas sehari-hari. Kegiatan sehari-hari yang berkaitan dengan ruang lingkup gerak lutut antara lain berjalan, berdiri, duduk, jongkok, dan lain-lain. Adanya osteoartritis lutut akan membuat seseorang tidak dapat menjalankan aktivitas fungsionalnya dengan baik (Susilawati et al., 2015). Aktivitas fungsional diukur menggunakan WOMAC (Western Ontario dan McMaster Universities Arthritis Index).

Variabel bebas dalam penelitian ini adalah latihan penguatan dengan menggunakan elastic band dan fisioterapi secara konvensional, yaitu infra red dan
TENS (transcutaneous electrical nerve stimulation). Variabel terikat pada penelitian ini adalah kemampuan fungsional pada penderita osteoarthritis lutut. Pengukuran kemampuan fungsional menggunakan WOMEC (Western Ontario and McMaster Universities Arthritis Index).

Latihan ini dilakukan dengan menggunakan perlawanan dari luar atau tubuh kita. Itu dilakukan secara teratur, terencana, dan berulang kali (Baechle \& Earle, 2008). Mereka dilakukan dengan prosedur sistematis otot atau kelompok otot untuk mengontrol beban berat (resistansi) dalam waktu yang singkat (Kisner \& Colby, 2012). Pada penelitian ini latihan penguatan dilakukan dengan menggunakan elastic band. Elastic band adalah alat sederhana yang digunakan untuk berbagai macam latihan fisik. Mudah dibawa, murah, dan banyak digunakan untuk meningkatkan kekuatan otot dan daya ledak. Kurva elastic band dikaitkan dengan peningkatan kekuatan dan nilai tegangan.

Semakin besar elastic band yang diregangkan, semakin tinggi tahanannya terhadap perpanjangan / ekstensi lebih lanjut. Menggunakan elastic band adalah cara mudah untuk meningkatkan intensitas latihan sekaligus menghindari risiko kelebihan beban. Alat ini digunakan karena elastisitasnya dan kemampuannya untuk kembali ke ukuran semula (Uchida, 2016).

Latihan diberikan dua kali seminggu selama empat minggu dengan satu set 6 perangkat latihan dan diajarkan kepada mereka pada awalnya dengan elastic band elastis. Latihan yang dilakukan adalah dorsi fleksi ankle, plantar fleksi ankle, ekstensi lutut, tekan kaki, angkat kaki lurus, dan 
abduksi hip. Para reponden diminta melakukan latihan dengan frekuensi latihan sekali sehari selama 25 menit, dua kali seminggu (Dhar \& Agarwal, 2015).

Dorsi fleksi ankle dimaksudkan untuk memperkuat otot-otot di tungkai bawah. Fisioterapis menginstruksikan responden untuk duduk dan meluruskan kedua kaki dan kemudian melilitkan elastic band di sekelilingnya. Fisioterapis memegang ujung elastic band di kedua tangan dan telapak tangannya saling berhadapan dengan tangan lurus dan responden menggerakkan kaki ke arah yang berlawanan sebagai elastic band.

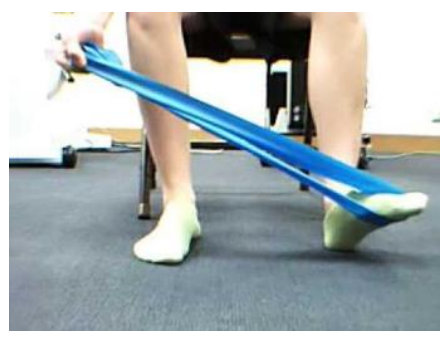

Gambar 1. Penggunaan elastic band dengan gerakan dorsi fleksi ankle (Yu et al., 2013)

Plantar fleksi ankle ditujukan untuk memperkuat otot-otot tungkai bawah bagian posterior. Responden penelitian ini diminta untuk duduk dan meluruskan kedua kaki dan sedikit diangkat ke arah kepala, kemudian dililitkan dengan elastic band, pegang kedua ujung elastic band pada kedua tangan dan kedua telapak tangan saling berhadapan dengan tangan lurus (bisa dilakukan secara pasif / dibantu oleh orang lain). Responden diperintahkan untuk menggerakkan kaki berlawanan dengan elastic band sebisa mungkin.

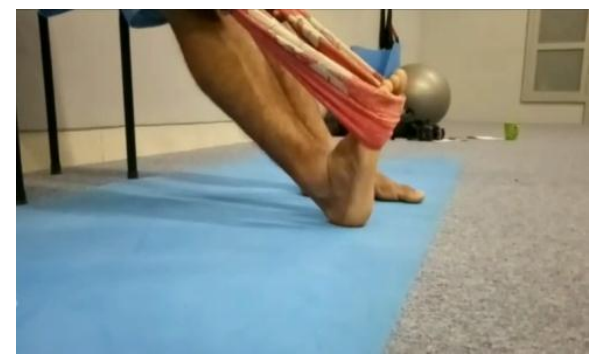

Gambar 2. Penggunaan elastic band dengan gerakan plantar fleksi ankle (Yu et al., 2013)

Ekstensi lutut digunakan untuk memperkuat otot-otot di paha bagian anterior. Di sini, responden duduk di atas kursi, kemudian mengikat salah satu kaki dengan elastic band pada kaki dengan posisi elastic band bersilang. Responden diinstruksikan untuk meluruskan kaki sebanyak mungkin.

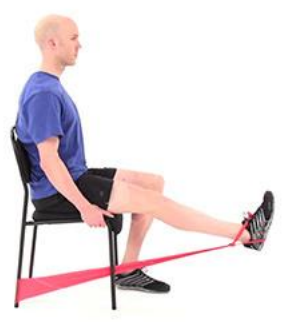

Gambar 3. Penggunaan elastic band dengan gerakan ekstensi lutut (Dhar \& Agarwal 2015)

Leg press dimaksudkan untuk memperkuat otot-otot di paha dan tungkai bawah. Responden duduk di kursi dengan kaki lurus ke depan dan tumit diletakkan di lantai sehingga ujung jari kaki menghadap ke atas. Elastic band ditempatkan di sol dan ujung elastic band ditarik. Kemudian kaki diangkat sampai bengkok. 


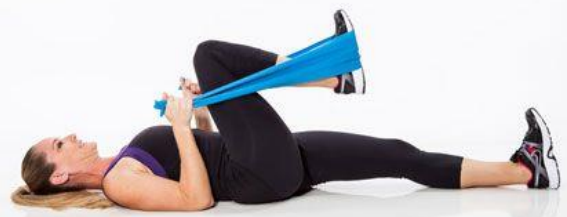

Gambar 4. Penggunaan elastic band dengan gerakan leg press (Yu et al., 2013)

Angkat tungkai lurus bertujuan untuk memperkuat otot-otot di paha dan tungkai bawah. Responden berbaring telentang dengan elastic band yang diikatkan pada salah satu kaki, kemudian diminta untuk mengangkatnya sebanyak mungkin.

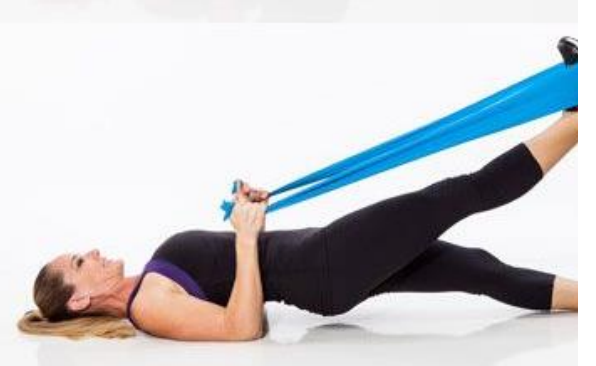

Gambar 5. Penggunaan elastic band dengan gerakan mengangkat kaki lurus (Dhar \& Agarwal 2015)

Abduksi hip dilakukan untuk memperkuat otot-otot di paha bagian lateral. Responden berdiri dengan satu kaki diikat dengan elastic band di pergelangan kaki dan kemudian kaki lainnya berfungsi sebagai penahan agar elastic band tidak terlalu longgar. Dia diinstruksikan untuk menggerakkan kaki menggunakan elastis dan keluar.

Penelitian ini dilakukan oleh enumerator (fisioterapis). Sebelum melakukan penelitian, enumerator menjelaskan beberapa hal kepada responden. Responden diminta mengisi informed consent, dijelaskan prosedur penelitian, dijelaskan manfaat yang diperoleh dari penelitian ini, serta mendapat terapi standar dari fisioterapis. Peneliti melakukan penilaian kemampuan fungsional sebelum dan sesuai pemberian intervensi, kemudian memberikan latihan penguatan dengan menggunakan elastic band. Setelah data diperoleh, peneliti mengolah data dengan menggunakan alat aplikasi statistik kemudian dilakukan analisis.
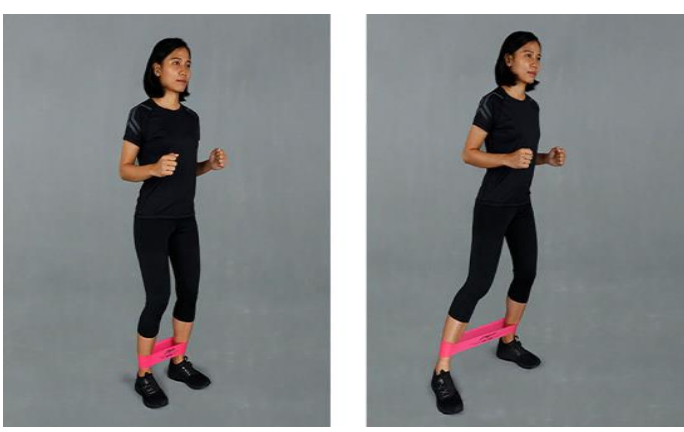

Gambar 6. Penggunaan elastic band dengan gerakan abduksi hip (Jensen et al., 2012)

Data dalam penelitian ini diolah dengan menggunakan program software SPSS. Analisis data dilakukan dengan menggunakan data non parametrik. Tes pertama untuk mengetahui pengaruh latihan penguatan dengan elastic band terhadap peningkatan kemampuan fungsional pasien osteoartritis pada kelompok perlakuan dan kontrol. Tes ini adalah tes bertanda tangan Wilcoxon. Uji Mann-Whitney digunakan untuk mengetahui perbedaan pengaruh antara kelompok perlakuan dan kelompok kontrol. 


\section{HASIL DAN PEMBAHASAN}

Tabel 11 Karakteristik Responden

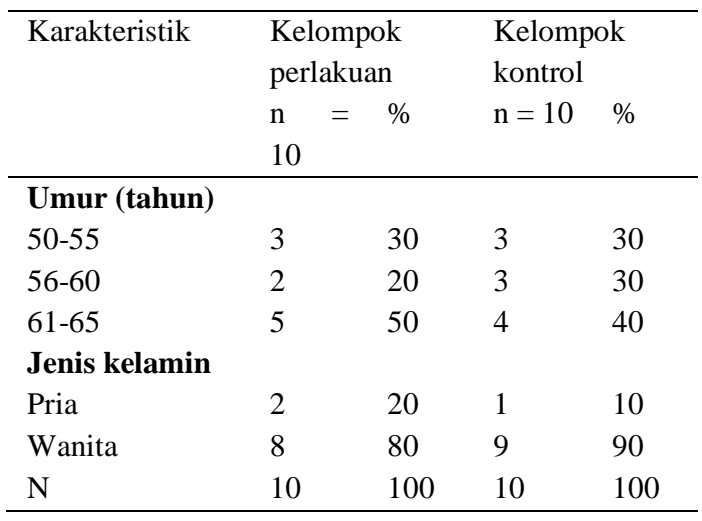

Berdasarkan Tabel 1 terlihat bahwa sebagian besar responden berusia 61-65 tahun (45\%). Berdasarkan jenis kelamin, sebagian besar berjenis kelamin perempuan (80\%), sedangkan pada kelompok kontrol 1 orang berjenis kelamin laki-laki dengan persentase $10 \%$ dan $90 \%$ perempuan.

WOMAC digunakan untuk mengukur aktivitas fungsional osteoartritis lutut. Tabel 2 menunjukkan skor WOMAC.

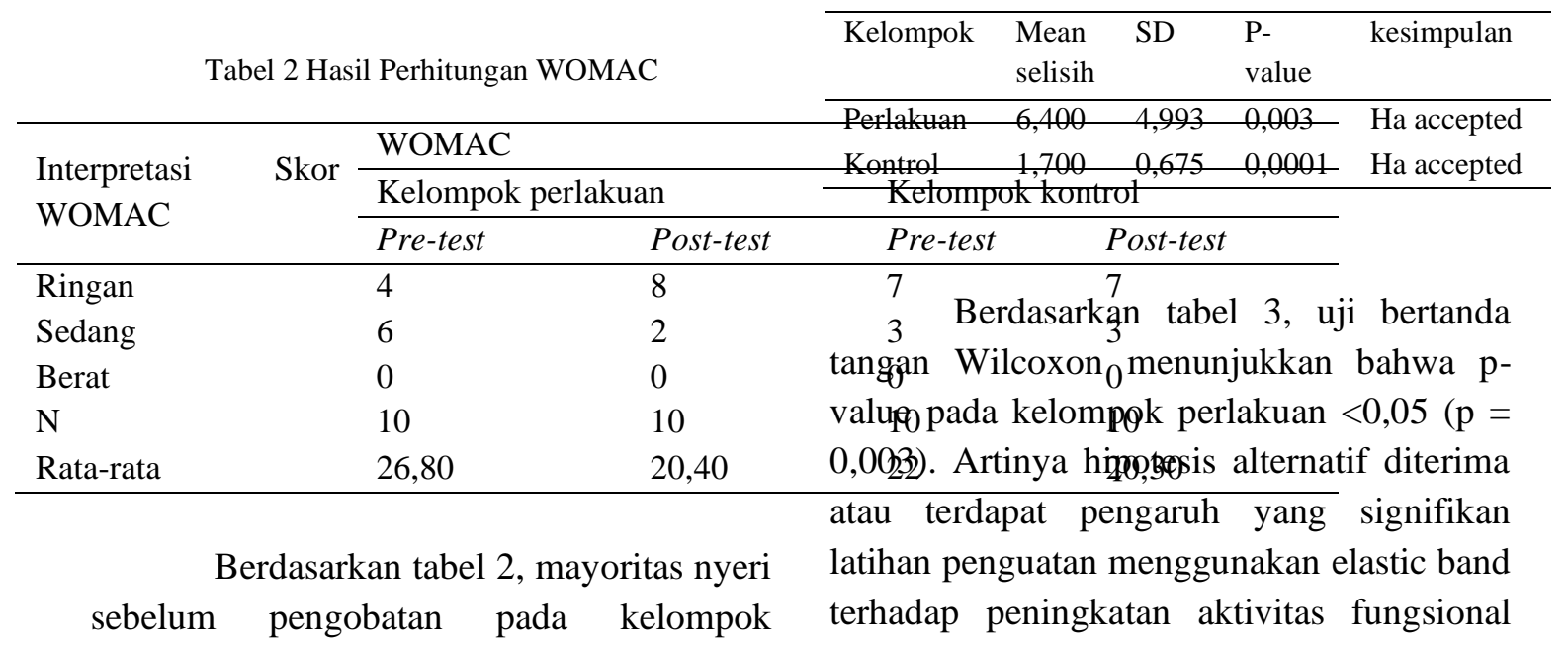

perlakuan adalah sedang dan berubah menjadi ringan setelah pengobatan. Di sisi lain, tidak ada perubahan jumlah nyeri pada kelompok kontrol. Indeks Osteoartritis Universitas Ontario Barat dan McMaster (WOMAC) adalah salah satu instrumen hasil OA yang paling sering digunakan, terutama pada OA lutut. WOMAC menghasilkan nilai fungsional yang diperoleh melalui kuesioner untuk mengukur nyeri sendi dan kecacatan pada pasien OA lutut (Golightly et al., 2012). Penelitian yang dilakukan di Marokok dengan 71 responden yang diberikan dua kali dengan interval 24-48 jam menunjukkan nilai reliabilitas WOMAC yang baik yaitu nilai ICC sebesar 0,91. Parameter WOMAC antara lain $0=$ tidak nyeri, $1=$ ringan, $2=$ sedang, 3 = berat, 4 = ekstrim dengan interpretasi skor total WOMAC 0-24 ringan, 24-48 sedang, 48-72 berat dan 72 -96 sangat parah (Faik et al., 2008).

Uji Wilcoxon dilakukan untuk membandingkan kelompok perlakuan dan kelompok kontrol sebelum dan sesudah perlakuan diberikan.

Tabel 3 Uji Pengaruh dengan Wilcoxon sign test 
pada penderita osteoartritis lutut. Sedangkan pada kelompok kontrol, nilai $\mathrm{p}$ kurang dari 0,05. Artinya Ha diterima.

Uji perbedaan pengaruh dilakukan dengan uji Mann Whitney.

Tabel 4 Uji Beda Pengaruh menggunakan Mann Whitney.

\begin{tabular}{lll}
\hline $\begin{array}{l}\text { Difference pre- } \\
\text { test post-test }\end{array}$ & p-value & conclusion \\
\hline WOMAC score & 0,981 & $\begin{array}{l}\text { No } \\
\text { significant }\end{array}$ \\
\hline
\end{tabular}

Tabel 4 menunjukkan bahwa tidak terdapat perbedaan yang bermakna antara kelompok perlakuan yang diberikan intervensi latihan perkuatan menggunakan elastic band dengan kelompok kontrol yang hanya diberikan intervensi IR dan TENS. Tabel 2 menunjukkan hasil perhitungan WOMAC pada kelompok perlakuan dengan rata-rata 26,80 sampai dengan 20,40 untuk pre dan post tes dan pada kelompok kontrol adalah 22 sampai 20,30. Perlakuan yang diberikan pada kelompok perlakuan memiliki pengaruh yang lebih berbeda dibandingkan dengan kelompok kontrol, namun berdasarkan uji beda didapatkan hasil tidak ada pengaruh yang signifikan antara kelompok perlakuan dan kelompok kontrol.

OA adalah penyakit osteoartikuler kronis, progresif, dan degeneratif yang ditandai dengan artralgia, kekakuan sendi, dan keterbatasan fungsi (Yildiriim et al., 2015). Seiring dengan bertambahnya usia maka terjadi proses degenerasi pada persendian yang mengakibatkan degenerasi tulang rawan secara progresif pada persendian lutut, yang dapat dipengaruhi oleh beberapa faktor yaitu obesitas, aktivitas fisik, dan lingkungan kerja sehingga dapat menurunkan aktivitas fungsional (Bhatia). dkk., 2013).

Berdasarkan hasil penelitian didapatkan tiga laki-laki dan 17 perempuan sebagai responden. Menurut Hame \& Alexander (2013), perbedaan presentasi dan perkembangan osteoartritis lutut pada wanita dibandingkan dengan pria disebabkan oleh penyebab multifaktorial dan termasuk perbedaan anatomi, trauma sebelumnya, serta masalah genetik dan hormonal. Perbedaan anatomi antara pria dan wanita merupakan salah satu faktor penyebab terjadinya osteoartritis antara lain penyempitan tulang paha, patela tipis, sudut paha depan yang lebih besar, dan perbedaan ukuran tibialis condylar serta perbedaan hormonal antara pria dan wanita yang mungkin terjadi. berperan dalam perkembangan osteoartritis. Wanita pascamenopause memiliki peningkatan risiko terkena artritis dan hal ini dikaitkan dengan penurunan estrogen dari waktu ke waktu.

Berdasarkan analisis data, perhitungan nilai WOMAC yang digunakan untuk mengetahui pengaruh latihan penguatan menggunakan elastic band terhadap peningkatan aktivitas fungsional pada penderita osteoartritis lutut dapat dilihat pada tabel 3. Hasil uji statistik menunjukkan p-value $<0,05$ atau signifikan. Hal ini sejalan dengan penelitian yang dilakukan oleh Lindayani (2018) yang membandingkan kelompok senam elastic band dengan kelompok senam isometrik kuadrisep. Hasil kedua teknik didapatkan $\mathrm{p}=0,000$ yang berarti tidak ada pengaruh kedua latihan tersebut terhadap kemampuan fungsional pasien osteoartritis lutut. Menurut Dhar \& 
Agarwal (2015), latihan penguatan dengan elastic band pada lutut efektif mengurangi nyeri dan kecacatan serta meningkatkan fungsi fisik pada pasien OA lutut. Latihan dengan band resistensi elastis digunakan sebagai alat untuk mengembalikan fungsi otot \& sendi untuk pengkondisian dan peningkatan kekuatan otot.

Terapi radiasi infra merah dapat meningkatkan aliran darah dan jaringan metabolisme, mengendurkan otot, dan meningkatkan stabilitas, yang dapat berkontribusi pada penurunan intensitas nyeri yang signifikan (Ihegihu, 2018). Nejati dkk. (2015), TENS adalah modalitas yang mengurangi rasa sakit dan membuktikan fungsi pada pasien OA lutut. Ini adalah masalah sepele dibandingkan dengan latihan penguatan dan hidroterapi. Setelah evaluasi pasien dilakukan dengan follow up satu tahun, ditemukan bahwa nyeri yang terjadi saat istirahat (VAS) dan selama pergerakan lutut (item nyeri pada kuesioner Koos) lebih sedikit dibandingkan pada kelompok kontrol. Kemampuan mereka untuk melakukan aktivitas sehari-hari seperti jalan kaki dan mandi juga bagus.

Menurut penelitian yang dilakukan oleh Lee et al. (2018), ketika elastic band diberikan, metabolisme basal dalam tubuh meningkat. Selain itu, tingkat sensitivitas insulin dan fungsi neuromuskuler juga meningkat dan berpengaruh terhadap peningkatan fungsional. Elastic band dengan menggunakan thera-band akan memberikan efek isotonik, yaitu dapat meningkatkan fungsi viseral dan volume pada otot akibat kerja metabolisme, dan suplai darah O2 menjadi lebih lancar dibandingkan dengan latihan ketahanan lainnya.
Sinar infra merah merupakan salah satu jenis radiasi elektromagnetik yang meliputi panjang gelombang antara $760 \mathrm{~nm}$ $100.000 \mathrm{~nm}$. Beberapa penelitian telah melaporkan bahwa IR dapat meningkatkan penyembuhan luka kulit dan mengurangi rasa sakit; modalitas ini sering digunakan pada kasus cedera muskuloskeletal. Pemanasan kulit yang superfisial akan menimbulkan efek fisiologis yang berfungsi untuk proses penyembuhan (Tsai \& Hamblin, 2017). Lama pemberian IR 15 menit dengan jarak 30-40 $\mathrm{cm}$. IR dapat diberikan 2-3 kali seminggu untuk mengurangi nyeri yang terjadi pada kasus OA.

Aplikasi TENS dalam dunia medis dan olahraga digunakan untuk tujuan rehabilitasi, pelatihan, dan pemulihan. Secara klinis dan terapeutik, perawatan berbasis TENS membantu latihan menahan beban dan ketahanan otot. Efek yang diharapkan, yang pertama adalah peningkatan aliran darah di otot dan penghancuran metabolit otot. Efek kedua adalah pengurangan nyeri otot melalui efek analgesik. Peningkatan aliran darah ke otot dapat terjadi akibat metabolit vasoaktif yang berasal dari kontraksi otot. Stimulasi listrik dipercaya dapat mengubah aliran darah (Miller et al., 2016). TENS memiliki manfaat untuk mengurangi intensitas nyeri dan, berbeda dengan menghilangkan nyeri dengan obat-obatan, karena TENS tidak menyebabkan kecanduan, tidak menyebabkan kantuk dan mual, serta dapat dilakukan kapan saja sesuai kebutuhan.

\section{KESIMPULAN}

Berdasarkan hasil penelitian dan pembahasan diatas dapat disimpulkan bahwa: terdapat pengaruh latihan penguatan 
menggunakan elastic band terhadap peningkatan aktivitas fungsional pada penderita osteoartritis lutut. Tidak ada perbedaan yang signifikan antara latihan Penguatan dengan Elastic band dengan pemberian sinar Infra merah, TENS untuk meningkatkan aktivitas fungsional pada pasien osteoartritis lutut. Disarankan agar penelitian selanjutnya dapat mengontrol waktu istirahat responden, tingkat psikologis responden serta mengukur langsung aktivasi otot.

\section{PENGAKUAN}

Ucapan terimakasih penulis ucapkan kepada Rektor UMS beserta jajarannya, Dekan Fakultas Ilmu Kesehatan beserta jajarannya, serta Ketua Program Studi Fisioterapi beserta jajarannya. Terima kasih juga kami sampaikan kepada semua pihak yang tidak dapat disebutkan satu persatu.

\section{DAFTAR PUSTAKA}

Bhatia, D., Bejarano, T., \& Novo, M. (2013). Current interventions in the management of knee osteoarthritis. Journal of pharmacy \& bio-allied sciences, 5(1), 30.

Berg, W. B. Van Den. (2011). Osteoarthritis year 2010 in review: pathomechanisms. Osteoarthritis and Cartilage, 19(4), 338341. https://doi.org/10.1016/j.joca.2011.01.02 2

Carlos, L. J. (2013). Training Program. Clinical Medicine. Department of Medicine, Division of Rheumatology and Immunology. University of Miami. Terjemahan Leonard M Miller. Editors
Herbert S Diamond. 2013 School of Medicine. USA.

Dhar, S., \& Agarwal, S. (2015). Effectiveness of an Elastic Band Exercise Protocol in Tri-Compartmental Osteoarthritis of the Knee. Indian Journal of Physiotherapy and Occupational Therapy - An International Journal, 9(2), 176. https://doi.org/10.5958/09735674.2015.00076.3

Dreier, R. (2010). Hypertrophic differentiation of chondrocytes in osteoarthritis : the developmental aspect of degenerative joint disorders

Faik, A., Amine, B., Bahiri, R., \& Abouqal, R. (2008). Translation and validation of Moroccan Western Ontario and McMaster Universities ( WOMAC ) Osteoarthritis Index in knee osteoarthritis Translation and validation of Moroccan Western Ontario and Mc Master Universities ( WOMAC ) osteoarthritis index in knee osteoarthritis. May 2015. https://doi.org/10.1007/s00296-007$\underline{0498-\mathrm{Z}}$

Golightly, Y., Allen, K., \& Caine, D. (2012). Exercise Programs for Patients with Osteoarthritis. Phys Sportsmed, 40(4), 52-65. https://doi.org/10.3810/psm.2012.11.198 8.A

Hame, S. L., \& Alexander, R. A. (2013). Knee osteoarthritis in women. Current Reviews in Musculoskeletal Medicine, 6(2), 182-187. https://doi.org/10.1007/s12178-0139164-0

Heidari, B., 2011, Knee Osteoarthritis Prevalence, Risk Factor, Phatogenesis 
And Features: Part I, Caspian Journal of Internal Medication, 2, 205-212.

Kisner, C.,, \& Collby, L. A. (2018). Therapeutic Exercise. (J. A. Piinne \& M. A. Duffield, Eds.) (7th ed.). E.A. Davis Company.

Lee, J. W., Kim, S. B., \& Kim, S. W. (2018). Effects of elastic band exercises on physical ability and muscular topography of elderly females. Journal of Physical Therapy Science, 30(2), 248-251. https://doi.org/10.1589/jpts.30.248

Lescher, Penelope J. 2014. "Patologi Untuk Fisioterapi". Jakarta: EGC.

Nejati, P., Farzinmehr, A., \& Moradi-Lakeh, M. (2015). The effect of exercise therapy on knee osteoarthritis: A randomized clinical trial. Medical Journal of the Islamic Republic of Iran, 29, 1-9.

Ringannyaosteoartritis, D. A. N. B. (2014) 'Hubungan Antara Faktor Risiko

Kuntono, P.H. 2011. Nyeri Secara Umum Dan Osteoarthritis Lutut dari Aspek Fisioterapi. Ed: 1.Osteoartritis'

Riberio et al. 2009. “ Pengaruh Latihan Beban Menggunakan Theraband Terhadap Peningkatan Kemampuan Fungsional Jalan Pada Lansia."

Setiati, Siti. 2013. "Geriatric Medicine, Sarkopenia, Frailty Dan Kualitas Hidup Pasien Usia Lanjut: Tantangan Masa Depan Pendidikan , Penelitian Dan Pelayanan Kedokteran Di Indonesia."

Suhendriyo. 2014. Pengaruh Senam Ramathik Terhadap Pengurangan Rasa Nyeri Pada Penderita Osteoarhritis Lutut Di karangasem Surakarta. Jurnal Terpadu Ilmiah Kesehatan. Vol 3 No 1, Mei 2014, HIm 1-6.
Suriani1 \& Lesmana. 2014. "Latihan Theraband Lebih Baik Menurunkan Nyeri Daripada Latihan Quadricep Bench pada Osteoarthritis Genu”.

Susilawati, I., Tirtayasa, K., and Lesmana, S. I. 2015. Latihan Closed Kinetic Chain Lebih Baik Dari Pada Osteoarthritis Lutut Setelah Pemberian Micro Wave Diathermy (MWD) Dan Trans-cutaneus Electrical Nerves Stimulation (TENS). Sport And Fitness Journal. Volume 3 No 1: $26-34$

Tsai, S. R., \& Hamblin, M. R. (2017). Biological effects and medical applications of infrared radiation. Journal of Photochemistry and Photobiology B: Biology, 170(October), 197-207. https://doi.org/10.1016/j.jphotobiol.2017. 04.014

Uchida, M.C., Nishida, M.M., Sampaio, R.A.C., Moritani, T., and Arai, H. 2016. Thera-band or elastic band tension: reference values for physical activity. The Journal of Physical Therapy Science, 28(4): 1266-1271.

Usia, L. (2010). Hubungan antara Kekuatan Otot dan Daya Tahan Otot Anggota Gerak Bawah dengan Kemampuan Fungsional Program Pascasarjana.

Wirahardja \& Satya, R. (2014). Sindroma Geriatri pada Lansia di Komunitas Sebuah Monograf. Jakarta: Grafind

Yildiriim, M. A., Uçar, D., \& Öneş, K. (2015). Comparison of therapeutic duration of therapeutic ultrasound in patients with knee osteoarthritis. Journal of Physical Therapy Science, 27(12), 3667-3670.

https://doi.org/10.1589/jpts.27.3667 